\title{
EDUCAÇÃO E HEGEMONIA NOS QUADERNI DEL CARCERE de Antonio Gramsci (1891-1937)*
}

\author{
Cézar de Alencar de Toledo, \\ da Universidade Estadual de Maringá (UEM); \\ Jarbas Maurício Gomes, \\ da Universidade Federal de São Carlos (UFSCAR).
}

\begin{abstract}
Resumo: A luta pela hegemonia e a ação dos intelectuais na formação cultural dos grupos sociais são temas que compõem o eixo central das análises de Antonio Gramsci (1891-1937) que demonstrou a importância da educação para a consolidação de uma hegemonia, seja pela ação da educação escolar, seja pela educação não escolar, feita em partidos políticos e sindicatos. Este texto tem como objetivo avaliar as ideias que fundamentaram as proposições de Gramsci sobre a educação a partir da análise dos Quaderni del carcere, posto ter ele demonstrado que a ação educativa desenvolvida pelos grupos de intelectuais encontra-se impregnada de contradições que influenciam o desenvolvimento e o sucesso da elaboração da contra-hegemonia por parte das classes trabalhadoras.

Palavras-chave: Educação. Hegemonia. Antonio Gramsci. Quaderni del carcere.
\end{abstract}

INTRODUÇÃO

Dentre os temas recorrentes no pensamento de Antonio Gramsci (1891-1937), a questão da formação da consciência proletária se destaca como um dos elementos essenciais para a efetivação da hegemonia dos trabalhadores. Ele defendia que a conquista da hegemonia se encontrava atrelada à capacidade de articulação dos trabalhadores nos processos de

\footnotetext{
* Artigo recebido em 06/08/2012 e aprovado em 22/01/2013.
} 
organização das forças produtivas e políticas, por meio da instituição e de uma nova forma de organização social. Esse Estado, de ordem proletária, teria como fim a criação de uma nova ordem econômica e social. Gramsci defendia que a luta da classe operária pela hegemonia tinha como pressuposto a formação da consciência intelectual para que o domínio teórico-filosófico se transformasse em uma práxis política consciente, o que permitiria aos trabalhadores assumir a tarefa de organizar e governar a sociedade, tendo em vista o desenvolvimento de um novo sistema econômico e social.

Este texto' tem como objetivo analisar as proposições de Gramsci sobre a função da educação no processo de elaboração da contra-hegemonia, fundamentado na leitura dos Quaderni del carcere (QC). ${ }^{2}$ Partindo-se do pressuposto de que para Gramsci a formação intelectual dos trabalhadores se encontra diretamente ligada à luta pela obtenção de uma nova hegemonia, avaliamos as notas dos QC para identificar as contradições existentes no processo educativo das massas de trabalhadores. Se de um lado, ao analisar o cenário político e econômico da Itália na virada do século XIX para o século XX, Gramsci defendia que a formação intelectual dos trabalhadores era uma condição necessária à tomada do poder político e econômico - a fundação do Estado operário - e, a partir daí, a obtenção da hegemonia por parte dos trabalhadores, ele apontava também que essa mesma formação intelectual, quando operada pela classe burguesa, servia de instrumento para a sua manutenção como classe hegemônica.

Essas análises, encontram-se registradas nos Quaderni del carcere (Cadernos do cárcere), um conjunto de 33 cadernos escolares nos quais Gramsci anotou suas reflexões no período em que cumpriu pena de reclusão durante os anos de 1926 e 1937. Preso em função de medidas repressivas adotadas pelo regime fascista italiano, vivenciou, durante os primeiros anos de reclusão, dificuldades que o impediram de produzir e, sobretudo, registrar seu trabalho intelectual. Foi somente após seu julgamento em Roma e de sua transferência para a Casa Penal de Turi que - em 28 de janeiro de 1929, após ter recebido a permissão para escrever na cela -Gramsci iniciou o registro de suas reflexões. ${ }^{3}$

Ao obter permissão para escrever na cela, Gramsci pôs em prática seu plano de estudos que tinha como principal ponto de investigação a história do desenvolvimento italiano. Esse plano de estudos valorizava a relação das questões culturais sobre o desenvolvimento econômico da Itália e abordava a formação intelectual dos mais diversos estratos sociais e diferentes grupos político-econômicos da Itália (MUSITELLI, 1996; MORDENTI, 1996). Dentre os principais temas apontados por Gramsci, encontravam-se a história da 
formação dos intelectuais italianos e a influência da cultura burguesa no teatro e nos romances literários de gosto popular. ${ }^{4}$

As suas contribuições para a reflexão e o desenvolvimento do marxismo, os pressupostos de teoria da história, os temas ligados ao desenvolvimento do Estado, da organização da cultura, da luta pela hegemonia e a filosofia da práxis têm sido agregados por pesquisas em diferentes áreas das ciências sociais e humanas, com ênfase na educação (NOSELLA, 2004; SECCO, 2002; BIANCHI, 2007; SAVIANI, 2005; SOARES, 2000). Essas questões originaram e fundamentaram as análises de Gramsci e tornaram seu pensamento um referencial para as pesquisas no campo da educação e das teorias pedagógicas. Seu pensamento tem sido analisado na educação, fundamentando-se duas concepções distintas: a educação formal e a educação informal. No campo da educação formal, as pesquisas versam sobre a escola e a sua função social perante os grupos sociais e o Estado (MOCHCOVITCH, 1988; SOARES, 2000; NOSELLA, 2004, TAVARES DE JESUS, 2005; SCHLESENER, 2009). As pesquisas sobre a educação informal tratam dos aspectos relativos à formação cultural do homem que ocorre de maneira assistemática, distante dos canais oficiais do Estado (SCHLESENER, 2002; 2007; NETO et. al., 2009).

Se tomarmos como ponto de partida as condições políticoeconômicas e culturais com as quais a educação brasileira se deparou nas últimas décadas, o pensamento de Antonio Gramsci se tornou um referencial teórico relevante para a compreensão dos processos de implementação de teorias pedagógicas (SCHLESENER, 2009; ANGELI, 2009; RAGAZZINI, 2005), de discussão das temáticas relativas à construção de políticas públicas voltadas ao desenvolvimento do sistema educacional nacional e sobre o papel da educação na formação do trabalhador (NOSELLA, 2004; NETO et. al., 2009). A teoria gramsciana do Estado elucida as discussões sobre gestão e administração escolar que, mediante a implantação da proposta de gestão democrática da escola, aproximou a sociedade civil da gestão escolar por meio da representatividade política das instâncias colegiadas da escola (SOARES, 2000). As análises de Gramsci presentes nos QC possuem diversas relações com as questões pertinentes aos estudos do campo da educação. Dentre esses temas, a questão dos intelectuais e a organização da cultura aparecem como elementos pertinentes para as discussões educacionais, uma vez que a luta pela hegemonia configura-se como um momento educacional no qual a ação dos intelectuais determina o desenvolvimento e o resultado da própria ação revolucionária (MANACORDA, 2008; SAVIANI, 2005). 


\section{A cultura e a LUTA Pela hegemonia}

Desde a formulação do plano até a sua materialização na redação dos QC, o tema da formação cultural foi apresentado como um elemento central no processo de reflexão gramsciano e foi analisado tendo em conta o desenvolvimento histórico italiano. Ao avaliar as contradições do desenvolvimento da política e da economia, Gramsci discutiu as correlações existentes entre os diferentes grupos sociais e destacou as formas pelas quais a cultura era influenciada pela política e pela economia (SCHLESENER, 2002; 2007). Nos QC, a cultura figura como um conceito amplo e que se manifesta dialeticamente pela tensão entre organizações culturais distintas: a da classe conservadora e a da classe revolucionária. Outro aspecto do conceito de cultura é a sua indissociabilidade com a linguagem, a partir da qual se deu o processo de unificação cultural na Europa, ao mesmo tempo que os grupos subalternos tentaram estabelecer a sua organização cultural frente aos grupos dominantes (BARATTA, 2009).

A luta desenvolvida entre os grupos está relacionada à obtenção da capacidade diretiva, estabelecida por meio do exercício da direção política. Esse conflito é a materialização da luta pela hegemonia que, na cultura, encontra a expressão das contradições geradas pelo mundo da produção. Posto que a realidade é contraditória, o conflito cultural se constitui pela existência de diferentes concepções de mundo, materializadas no embate entre as crenças conservadoras e os sistemas culturais revolucionários. Esses se manifestam, na prática, por meio da renovação cultural, muitas vezes, em contradição com os elementos morais, religiosos e econômicos de ambos os grupos. A efetivação da hegemonia está na capacidade diretiva de um grupo sobre as questões político-culturais de uma sociedade (SCHLESENER, 2007). ${ }^{5}$

O conflito cultural é um componente da luta pela hegemonia que, uma vez estabelecida, permite ao grupo hegemônico exercer a direção cultural e política, visando a unificação dos sistemas culturais dos diferentes grupos que interagem em uma mesma sociedade. Dessa forma, a cultura torna-se a expressão da sociedade que tende à unificação da consciência. Para Gramsci, esse processo de formação cultural é real, na medida que a formação da consciência não elimina as contradições existentes entre os diferentes grupos sociais (QC 9, §57).

O homem conhece objetivamente enquanto a consciência é real para todo o gênero humano historicamente unificado em um sistema cultural unitário; mas esse processo histórico de unificação ocorre com o desaparecimento das contradições internas que afetam a sociedade humana, contradição que 
é a condição para a formação dos grupos e para o nascimento de ideologias que não se concretizam universalmente e se tornam obsoletas imediatamente após a sua origem [...]. Há, portanto, uma luta pela objetividade (para liberar-se das ideologias parciais e falaciosas) e esta luta é a própria luta pela unificação cultural do gênero humano [...]. (QC 11, §17, p. 1416)

O confronto ideológico entre classes favorece a formação e o fortalecimento da consciência dos grupos subalternos e o desenvolvimento da vontade coletiva que, para Gramsci, precisa ser nacional e popular (DIAS, 2000; COUTINHO, 2009). O movimento de fortalecimento da vontade coletiva - para a transformação e a superação de uma dada condição histórica - tem a capacidade de agir com energia suficiente ao ponto de derrubar a dominância de uma vontade coletiva já instituída, substituindo-a e dissolvendo sua capacidade de direcionamento político-cultural (SOARES, 2000). Essa iniciativa de confronto entre os grupos se dá mediante a ação dos intelectuais, considerados por Gramsci como organizadores e difusores da cultura e das concepções de mundo (MANACORDA, 2008; MUSITELLI, 1996; SOARES, 2000).

$A$ atividade de direção política - que os intelectuais exercem frente aos grupos sociais, em especial aos grupos subalternos - constitui-se como uma atividade pedagógica que expõe as contradições sociais e desmistifica a condição de dominação presente nas relações entre os grupos sociais (NOSELLA, 2004; SCHLESSENER, 2007). Pela ação dos intelectuais junto aos partidos políticos, os grupos subalternos vivem o processo de formação cultural com vista ao despertar das massas para a necessidade de elaboração de uma consciência critica. A formação dessa consciência, operada pelos intelectuais na figura do partido político, aponta para a elaboração e difusão de uma nova concepção de mundo que permita aos grupos subalternos atuarem no campo da cultura, com autonomia, frente ao modelo cultural dominante (SCHLESSENER, 2007).

A direção cultural é um momento de hegemonia em que um grupo exerce o domínio intelectual sobre demais. Nos QC, Gramsci especificou que esse momento se concretiza frente a dois tipos de ação diferentes. A hegemonia se consolida mediante a ação de direção exercida por meio do consenso adquirido junto aos grupos aliados à classe dominante e pela coerção aplicada sobre os grupos sociais adversários. O exercício de manutenção da hegemonia ocorre mediante o uso dessa coerção (GRUPPI, 1978; COSPITO, 2009).

Uma classe é dominante de dois modos, é "dirigente" e "dominante". É dirigente das classes aliadas, é dominante das classes adversárias. Assim uma classe, antes de ir ao poder, pode ser dirigente (e deve sê-lo); quando está 
no poder torna-se dominante, mas continua a ser "dirigente". [...] A direção política torna-se um aspecto do domínio, enquanto a absorção das elites das classes inimigas leva a decapitação destas e a sua impotência. Pode e deve ser uma "hegemonia política" mesmo antes de estar no governo e não deve contar somente com o poder e a força material que este lhe dá para exercitar a direção ou a hegemonia política. (QC 1, § 44, p. 41)

A luta pela hegemonia exercida pelos grupos sociais tem como fim o domínio em três esferas da sociedade: a política, a cultural e a econômica. A capacidade diretiva, adquirida por um grupo social em uma dessas três esferas, permite-lhe e lhe confere a hegemonia que sempre tende ao domínio intelectual e se consolida efetivamente na economia. Gramsci observou a tendência histórica para a unificação cultural dos grupos na Itália e apontou a capacidade de direção político-cultural dos grupos dominantes sobre os grupos subalternos, de maneira que a organização dos grupos subalternos reflete, de certo modo, o modelo hegemônico. ${ }^{6}$

A história dos grupos sociais subalternos é necessariamente desagregada e episódica. Não restam dúvidas de que na atividade histórica desses grupos há uma tendência para a unificação, ainda que seja a partir de um plano provisório, mas essa tendência é continuamente interrompida pelas iniciativas dos grupos dominantes e, portanto, só pode ser demonstrada em um ciclo histórico completo, se este se encerrou com êxito. Os grupos subalternos submetem-se sempre à iniciativa do grupo dominante, mesmo quando se rebelam e insurgem-se [...]. (QC 25, § 2, p. 2283)

As análises de Gramsci apontam para a constante submissão dos grupos subalternos às iniciativas dos grupos dominantes. Essa incapacidade de superação do modelo cultural estabelecido e difundido pelo grupo dirigente se deve à própria relação que as classes subalternas e revolucionárias possuem com a questão cultural (SCHLESSENER, 2002). O trabalho de elaboração da cultura e da formação da consciência da classe revolucionária ocorre por meio da organização dos partidos políticos. Esses, por sua vez, necessitam do trabalho intelectual para se desenvolverem como agentes educativos e produzirem uma organização que se estabeleça como cultura e, assim, façam frente ao modelo estabelecido pelo grupo dominante (DEL ROIO, 2007).

O processo de unificação dos grupos de subalternos, formados por camponeses e operários, teria como fim a formação de uma consciência de classe por intermédio da organização político-partidária. Caberia ao partido das classes subalternas unificadas, liderado pela classe operária, promover uma reforma moral e intelectual a partir da negação de sua própria condição. 
Esse processo de formação da consciência permitiria que, por intermédio do partido político e de sua capacidade organizativa, a classe subalterna atingisse o progresso intelectual das massas e, assim, adquirisse capacidade diretiva política e cultural (DEL ROIO, 2007).

\section{A AÇÃO DOS INTELECTUAIS E A LUTA HEGEMÔNICA: UM MOMENTO EDUCATIVO}

A ação dos intelectuais está atrelada à luta hegemônica e, quando operada pelos representantes dos grupos subalternos, tem o poder de produzir um movimento de oposição ao modelo cultural dominante. Há, no entanto, um entrave para a realização desse processo. As classes subalternas não desenvolveram, historicamente, sua capacidade intelectual, cabendo a organização da cultura às classes dominantes, as quais o fizeram por intermédio da ação dos intelectuais. Esses, ao exercerem a direção políticocultural e até mesmo moral, influenciam na elaboração da cultura, ao mesmo tempo que impedem as classes subalternas de se apropriarem dos elementos necessários à superação de sua condição.

A classe revolucionária é sempre fraca intelectualmente deste ponto de vista: luta pela construção de uma cultura que seja a expressão de uma classe consciente e responsável; além do mais, todos os descontentes e os perdedores da outra classe jogam ao seu lado para refazer uma posição. O mesmo não se pode dizer da velha classe conservadora, muito pelo contrário; e ainda a sua literatura de propaganda é pior e mais demagógica [...]. (QC 2, § 91, p. 249)

A luta pela hegemonia travada no processo de organização da sociedade civil configura-se como um momento educativo. Nesse, os intelectuais possuem um papel fundamental, decisivo e determinante para o desfecho desse conflito. A ação dos intelectuais, ampliada pela sua capacidade de estabelecer uma relação com os grupos sociais, torna-se decisiva para o resultado de um processo revolucionário; isso porque pode tender à renovação ou à conservação das concepções de mundo, implicando diretamente no processo de construção da cultura e no direcionamento político-cultural estabelecido entre aqueles que lutam pela obtenção da hegemonia.

Os intelectuais constituem um dos capítulos mais importantes do pensamento de Antonio Gramsci. As análises sobre a evolução histórica dos grupos de intelectuais ocupam o QC 12 e se focam em torno da distinção entre os tipos de intelectuais e a sua função no processo da luta pela hegemonia. As análises de Gramsci procuram estabelecer o papel assumido pelos intelectuais italianos no processo do desenvolvimento político, cultural e econômico 
da Itália. Ainda que suas reflexões estivessem voltadas para o progresso italiano, a questão dos intelectuais foi abordada de maneira aprofundada e se desenrolou tomando como ponto de partida uma série de questionamentos a respeito da origem dos intelectuais e a sua filiação a uma classe social.

Logo no início do QC 12, Gramsci se indaga: "Os intelectuais são um grupo autônomo e independente, ou cada grupo social tem sua própria categoria especializada de intelectuais?" (QC 12, § 1, p.1513). Esse primeiro questionamento indica a necessidade de reflexão e compreensão acerca da função dos intelectuais no desenvolvimento de uma dada sociedade. Gramsci, mais adiante, arguiu também sobre as possibilidades de entendimento da concepção de intelectual e dos critérios para distinguir as atividades desses das atividades desenvolvidas por outros grupos sociais.

Quais são os limites "máximos" da acepção de "intelectual"? É possível encontrar um critério unitário para caracterizar igualmente todas as diversas e variadas atividades intelectuais e para distingui-las, ao mesmo tempo e de modo essencial, das atividades dos outros agrupamentos sociais? (QC 12 , § 1, p. 1516)

Essas questões foram apresentadas junto a algumas advertências de Gramsci que - embora tratem da natureza de sua investigação sobre os intelectuais - nos remetem à relação da história dos intelectuais italianos com o avanço da cultura e da política, áreas essas consideradas, por ele, espaços fundamentais para o desenvolvimento da luta hegemônica. Essas advertências compõem sua crítica aos estudos anteriores que tratavam a questão dos intelectuais de forma estritamente sociológica. Ele apontou que seu estudo configurava-se mais como uma série de ensaios de história da cultura e de história da ciência política (QC 12, § 1).

Logo de início, no QC 12, Gramsci aponta a coexistência de dois grupos distintos de intelectuais. Os denominados intelectuais tradicionais, que tendem à conservação do estabelecido e defendem as concepções de mundo previamente instituídas e consolidadas, representando, assim, os interesses de uma classe conservadora. E os intelectuais que se originam de uma dada classe social como resposta às suas necessidades - denominados por Gramsci de intelectuais orgânicos; esses, de modo geral, opõem-se aos intelectuais tradicionais na luta pela hegemonia e representam não só a desconstrução do modelo cultural estabelecido, como também ressignificam a própria condição de intelectualidade.

Na compreensão do sentido histórico da ação dos intelectuais na elaboração da cultura e na luta hegemônica, Gramsci apontou que os grupos dominantes exercem sua influência sobre os grupos de intelectuais por dois 
meios. Primeiro, pela difusão de uma concepção geral de vida pela qual os intelectuais são atraídos se sentirem parte integrante do sistema político e econômico dominante, assumindo para si o modelo cultural proposto por tal grupo. E segundo, pelo exercício da atividade educativa que, como uma atividade de caráter econômico, permite a eles ascender em direção ao nível econômico da classe dominante.

A hegemonia de um centro diretivo sobre os intelectuais se afirma através de duas linhas principais: 1) uma concepção geral da vida, uma filosofia (Gioberti), a qual ofereça aos seguidores uma "dignidade" intelectual que dê um principio de diferenciação e um elemento de luta contra as velhas ideologias coercitivamente dominantes; 2 ) um programa escolar, um princípio educativo e pedagógico original, que alcance e dê uma atividade própria, em seu campo técnico, àquela fração dos intelectuais que é a mais homogênea e a mais numerosa (os educadores, desde o professor primário até os professores universitários). (QC 19, § 27, p. 2047)

Dessa forma, ao valorizá-los e lhes permitir a ascensão social, o grupo hegemônico obtém o consenso dos grupos de intelectuais que passam a defender uma determinada concepção de vida, seja nos espaços formais da educação como a escola, seja em espaços informais que, no momento histórico de Gramsci, eram os sindicatos, os partidos políticos e em especial os conselhos de fábrica (MANACORDA, 2008; DIAS, 2000; DEL ROIO, 2005). A influência do grupo dirigente sobre os intelectuais incide, de forma direta, sobre a educação das massas, uma vez que esse é o espaço propício para a inserção dos ideais dos grupos dirigentes na cultura dos grupos subalternos. Pela ação educativa, torna-se possível influenciar os grupos de oposição sem que esses tomem consciência da força coercitiva desenvolvida sobre eles (SOARES, 2000; DIAS, 2000; DEL ROIO, 2005). Nesse sentido, a educação está relacionada ao processo de legitimação e consolidação da hegemonia, ao responder à necessidade de consenso e de domínio. Gramsci apontou que a atividade educativa exercida pelos intelectuais na escola representa um momento da luta pela hegemonia (MANACORDA, 2008; NOSELLA, 2004). Esse momento possui duplo significado: primeiro, pelo domínio econômico dos grupos hegemônicos sobre os intelectuais; e, segundo, pelo processo de disseminação da ideologia pela qual os próprios intelectuais dão o testemunho da filosofia e da concepção de vida do grupo dirigente.

As atividades escolares de caráter liberal ou liberalizante têm um grande significado para afirmar o mecanismo da hegemonia liberal dos moderados sobre os intelectuais. A atividade escolar, em todos os seus graus, tem uma importância enorme, inclusive econômica, para os intelectuais de todos os 
níveis: naquela época, até mais do que hoje, dada a estreiteza dos quadros sociais e os poucos caminhos abertos à iniciativa dos pequenos burgueses (hoje: jornalismo, movimento dos partidos, indústria, aparelho estatal extensíssimo etc. ampliaram de modo extraordinário as possibilidades de emprego). (QC 19, § 27, p. 2047)

Gramsci defendia que a ação educacional ocorrida formalmente na escola não é exclusiva e que os processos educativos informais desempenham um papel importante na formação do sujeito, posto que promovem o contato direto com a realidade e permitem, por meio da vivência do cotidiano, a compreensão da dinâmica real da vida. Esse processo de educação informal estabelece-se como um contraponto na formação dos indivíduos e tem o poder de evidenciar as contradições acobertadas pelo conformismo cultural desenvolvido pela educação formal.

De resto, a "escola" (isso é, a atividade educativa direta) é somente uma fração da vida do aluno, o qual entra em contato tanto com a sociedade humana quanto com a societas rerum, formando-se critérios a partir dessas fontes "extra-escolares" muito mais importantes do que habitualmente se crê. A escola única, intelectual e manual, tem ainda esta vantagem: a de colocar o menino em contato, ao mesmo tempo, com a história humana e com a história das "coisas", sob o controle do professor. (QC 1, §123, p. 114)

As análises de Gramsci sobre a luta hegemônica apontaram para a necessidade de compreensão do papel do processo de formação cultural dos grupos sociais, desenvolvidos dentro e fora da educação escolar. Ao mesmo tempo que a educação representa a possibilidade de superação de uma dada condição histórica, ela é responsável pela manutenção da estrutura social vigente. Para tanto, entranhar-se nos elementos fundantes do pensamento de Gramsci (e discuti-los) conduz para além da percepção de que a formação da consciência é indispensável para a superação de uma dada hegemonia. Esse processo se desenvolve a partir de tensões dialéticas e abrange todas as esferas da construção da vida material, uma vez que é possível afirmar que os intelectuais, sem consciência da direção política e moral exercida dentro de uma sociedade, não conseguem estabelecer uma hegemonia.

\section{CONCLUSÃO}

As análises de Antonio Gramsci sobre a evolução histórica italiana serviram de fundamento para a elaboração de uma série de categorias analíticas que lhe permitiram a compreensão das contradições históricas envolvidas no processo de desenvolvimento político, econômico e cultural 
da Itália. Suas análises sobre a organização do Estado Moderno e dos agentes envolvidos no progresso cultural propiciaram-lhe ampliar e aprofundar as discussões relativas ao marxismo e à leitura da história. Delas, conceitos como hegemonia, intelectuais, práxis e Estado foram ressignificados para explicar as tentativas dos grupos subalternos de superar a realidade material, derivada da expansão do capitalismo e de suas forças produtivas.

As análises de Gramsci sobre a evolução da cultura e a luta hegemônica convergem para a questão dos intelectuais, cuja ação educativa está na base dessa luta e é responsável pelo processo de consolidação da hegemonia de um grupo social sobre os demais. Discutir as análises de Gramsci se torna, assim, um instrumento que possibilita a compreensão das condições que se impõem à educação na atualidade. Guardadas as características de cada momento histórico, a avaliação dos desdobramentos da luta hegemônica no campo da cultura permite a compreensão da organização das políticas educacionais e dos objetivos da educação.

A luta das classes subalternas pela formação da consciência crítica se encontra atrelada à ação dos intelectuais e à possibilidade de educação das massas para a revolução. Gramsci apontou que esse processo deve estabelecer pontos de ruptura com o modelo cultural hegemônico, de maneira que se possa estabelecer a possibilidade de superação da realidade. A preocupação de Gramsci com a formação dos subalternos tornou seu pensamento um objeto de estudo valioso para as pesquisas em educação, na medida que suas reflexões se desenvolvem no sentido de propor um modelo de escola e de formação do homem para uma sociedade em transformação. Ao se nomear como revolucionária, sua visão educacional e político-cultural distingue-se do modelo hegemônico decorrente da ascensão da classe burguesa e da expansão das forças produtivas do capitalismo.

\section{EDUCATION AND HEGEMONY IN GRAMSCI'S QUADERNI DEL CARCERE}

ABSTRACT: The struggle for hegemony and the action of intellectuals in the cultural formation of social groups, subjects which are the central theme of Antonio Gramsci's (1891-1937) analyses, have shown the importance of education for the consolidation of a hegemony, whether through schooling or non-school education, carried out by political parties and trade unions. The aim of this paper is to analyze the ideas underlying Gramsci's propositions on education taking as its starting point a study of the Quaderni del carcere, as it showed that the educational action undertaken by intellectual groups was impregnated by/with contradictions which influenced the development and success of the working classes in drawing up a counter hegemony.

KEYWORDs: Education. Hegemony. Antonio Gramsci. Quaderni del Carcere. 
EDUCACIÓNY HEGEMONÍA EN LOS QUADERNI DEL CARCERE DE ANTONIO GRAMSCI (1891-1937)

RESUMEN: La lucha por la hegemonía y la acción de los intelectuales en la formación cultural de los grupos sociales son temas que componen el eje central de los análisis de Antonio Gramsci (1891-1937), quien demostró la importancia de la educación para la consolidación de una hegemonía, sea por la acción de la educación escolar, o bien por la educación no escolar, impartida en partidos políticos y sindicatos. Este texto tiene como objetivo analizar las ideas que fundamentaron las propuestas de Gramsci sobre la educación a partir del análisis de los Quaderni del carcere, una vez que demostró que la acción educativa desarrollada por los grupos de intelectuales se encuentra impregnada de contradicciones que influencian el desarrollo y el éxito de la elaboración de la contra hegemonía por parte de las clases trabajadoras.

Palavras-claves: Educación. Hegemonía. Antonio Gramsci. Quaderni del Carcere.

\section{NOTAS}

1. Trabalho apresentado no IV Seminário Científico Internacional Teoria Política do Socialismo: "Antônio Gramsci - as periferias e os subalternos", na UNESP de Marília, em agosto de 2011.

2. Os textos dos Quaderni del carcere serão citados a partir da Edizione Critica dell'Istituto Gramsci a cura de Valentino Gerratana (2007), com tradução livre do italiano para o português. As menções aos Quaderni serão feitas pela apresentação da abreviação QC e as citações serão indicadas pelos números do Caderno, do parágrafo e da página (QC 1, § 1, p. 1).

3. Desde o momento de sua prisão, em 18 de novembro de 1926, até seu julgamento em 4 de junho de 1928, Gramsci era transferido constantemente de uma casa penal a outra. Essas transferências não propiciavam um ambiente adequado ao estudo e ao desenvolvimento da atividade intelectual, dificultando até mesmo os trâmites legais, a partir dos quais, Gramsci e seus familiares solicitavam uma permissão para que ele pudesse escrever na cela. Quando recebeu sua sentença pelo tribunal de Roma em julho de 1928 e, por fim, foi transferido para a Casa Penal de Turi, na província de Bari, no início de julho, ele ainda demoraria alguns meses para iniciar a redação dos Cadernos. Em agosto daquele ano, foi-lhe designada uma cela individual e, em janeiro de 1929, a permissão para escrever na cela.

4. O plano de estudos foi apresentado na Carta a Tatiana, de 19 de março de 1927. A proposta de Gramsci contempla quatro grandes temas: a história dos intelectuais; questões de linguística comparada; a influência do teatro de Pirandello sobre a formação e a transformação do gosto teatral dos italianos; e, por fim, o gosto popular pelos romances (GRAMSCI, 1973). 
5. A sociedade em questão é a sociedade civil apresentada por Gramsci como o espaço natural das disputas hegemônicas de onde origina a ciência política (QC 11, § 65, p. 1493). Deve-se ter em conta que, para Gramsci, existem duas sociedades distintas que coexistem dentro de um Estado. No QC 6 Gramsci apresentou o Estado como a síntese dessas sociedades: "[...] Estado = Sociedade política + sociedade civil, isso é hegemonia encouraçada pela coerção" (QC 6, § 88, p. 763-764). A sociedade política é compreendida por Gramsci como a organização estatal que possui o poder político e a condição para o exercício da coerção por meio do direito legislativo; e a sociedade civil - a qual, por sua vez, compreende os segmentos que não participam do governo do Estado - comporta a união dos cidadãos destituídos do poder governamental que adquire influência política a partir do consenso das massas reunidas em torno de instituições e organizações privadas como sindicatos e partidos políticos.

6. No QC 6, Gramsci enfatizou a importância da hegemonia político-cultural na formação da sociedade civil, ao analisar a influência da concepção religiosa de mundo na organização cultural da sociedade. Gramsci indica que a sociedade civil deve ser entendida como a hegemonia política e cultural de um grupo sobre a totalidade da sociedade (QC 6, § 24, p. 703-704).

\section{REFERÊNCIAS}

ANGELI, J. M. Princípio da formação humana: a filosofia da práxis. In: PLATT, A. D.(Org). Curriculo e formação humana: princípios, saberes e gestão. Curitiba: Ed. CRV, 2009. p. 13-27.

BARATTA, G. Cultura. In: LIGUORI, G. L.; VOZA, P. Dizionario gramsciano 1926-1937. Roma: Carocci, 2009. p. 190-194.

BIANCHI, Á. Apresentação do dossiê "Gramsci e a política". Revista de Sociologia Política, Curitiba, n. 29, p. 7-14, nov. 2007.

COUTINHO, C. N. Gramsci. Porto Alegre: L\&PM: 1981.

COUTINHO, C. N. Volontà collettiva. In: LIGUORI, G. L.; VOZA, P. Dizionario gramsciano 1926-1937. Roma: Carocci, 2009. p. 900-902.

COSPITO, G. Egemonia. In: LIGUORI, G. L.; VOZA, P. Dizionario gramsciano 1926-1937. Roma: Carocci, 2009. p. 266-269.

DEL ROIO, M. Gramsci e a emancipação do subalterno. Revista de Sociologia Política, Curitiba, n. 29, p. 63-78, nov. 2007.

DEL ROIO, M. Os prismas de Gramsci: a fórmula política da frente única (1919-1926). São Paulo: Xamã, 2005.

DIAS, E. F. Gramsci em Turim: a construção do conceito de hegemonia. São Paulo: Xamã, 2000.

GRAMSCI, A. Lettere dal carcere: a cura di Sergio Caprioglio e Elsa Fubini. Turim: Einaudi, 1973. 
GRAMSCI, A. Quaderni del Carcere. Edizione crittica dell'Istituto Gramsci a cura di Valentino Gerratana. Torino: Einaudi, 2007. 4 vol.

GRUPPI, L. O conceito de hegemonia em Gramsci. 2. ed. Trad. Carlos Nelson Coutinho. Apresentação de Luiz Werneck Vianna. Rio de Janeiro: Edições Graal, 1978.

LIGUORI, G. Roteiros para Gramsci. Trad. Luiz Sérgio Henriques. Rio de Janeiro: Editora da UFRJ, 2007.

MANACORDA, M. A. O princípio educativo em Gramsci: americanismo e conformismo. 2. ed. brasileira. Trad. Willian Lagos. Campinas: Alínea, 2008.

MORDENTI, R. "Quaderni dal Carcere” di Antonio Gramsci. In: ROSA, A. A. (Curator). Letteratura Italiana Einaudi. Le Opere. Torino: Einaudi, 1996. v. IV-II.

MUSITELLI, M. P. Introduzione a Gramsci. Roma: Editori Laterza, 1996.

MOCHCOVITCH, L. G. Gramsci e a escola. São Paulo: Ática, 1988.

NETO, A. J. M. et. al. Trabalho, política e formação humana: interlocuções com Marx e Gramsci. São Paulo: Xamã, 2009.

NOSELLA, P. A escola de Gramsci. 3. ed. rev. e atual. São Paulo: Cortez, 2004.

RAGAZZINI, D. Teoria da personalidade na sociedade de massa: a contribuiç̧ão de Gramsci. Trad. Maria de Lourdes Menon. Campinas: Autores Associados, 2005.

SAVIANI, D. Gramsci na educação brasileira. In: RAGAZZINI, D. Teoria da personalidade na sociedade de massa: a contribuição de Gramsci. Trad. Maria de Lourdes Menon. Campinas: Autores Associados, 2005. p. 1-25.

SCHLESENER, A. H. A escola de Leonardo: política e educação nos escritos de Gramsci. Brasília: Liber Livro, 2009.

SCHLESENER, A. Hegemonia e cultura em Gramsci. 3. ed. Curitiba: Ed. UFPR, 2007.

SCHLESENER, A. Revolução e cultura em Gramsci. Curitiba: Ed. UFPR, 2002.

SECCO, L. Gramsci e o Brasil: recepção e difusão de suas ideias. São Paulo: Cortez, 2002.

SOARES, R. D. Gramsci, o Estado e a escola. Ijuí: Ed. UNIJUÍ. 2000.

TAVARES DE JESUS, A. O pensamento e a prática escolar de Gramsci. 2 ed. Campinas: Autores Associados, 2005.

Cézar de Alencar de Toledo: doutor em Educação pela Unicamp (1996); professor do Departamento de Fundamentos da Educação $e$ do Programa de Pós-Graduação em Educação da Universidade Estadual de Maringá (PR).

E-mail: caatoledo@uem.br 
Jarbas MAURício Gomes: doutorando em Educação no programa de Pós-Graduação em Educação da Universidade Federal de São Carlos; mestre em Educação pela Universidade Estadual de Maringá (2012); especialista em Pesquisa Educacional pela Universidade Estadual de Maringá (2009); graduado em Filosofia pela Universidade Estadual do Oeste do Paraná (2004).

E-mail: jarbasmauricio@gmail.com 